\title{
Formulation and optimization of gellan gum-poloxamer based dexamethasone mucoadhesive in situ gel
}

\author{
Seda RENÇBER $1 *$ (D), Sinem Yaprak KARAVANA 2 (D) \\ 1 Department of Pharmaceutical Technology, Faculty of Pharmacy, İzmir Katip Celebi University, İlzmir, Turkey. \\ 2 Department of Pharmaceutical Technology, Faculty of Pharmacy, Ege University, İzmir, Turkey. \\ * Corresponding Author. E-mail: seda.rencber@ikc.edu.tr (S.R.); Tel. +90-232-329 35 29-61 25.
}

Received: 22 April 2020 / Revised: 08 May 2020 / Accepted: 14 June 2020

ABSTRACT: The main objective of the present study was to formulate and evaluate mucoadhesive in situ buccal gels of dexamethasone based on gellan gum-poloxamer 407. Formulations were characterized for gelling capacity, drug content, $\mathrm{pH}$, viscosity, rheological studies, mechanical studies and in vitro drug release. The drug content, clarity and $\mathrm{pH}$ of the formulations were found to be satisfactory. Mucoadhesive in situ gels showed thermoresponsive behavior, existing as a liquid at room temperature and gel at $30-37^{\circ} \mathrm{C}$. Formulations exhibited pseudoplastic flow and typical gel-type mechanical spectra $\left(\mathrm{G}^{\prime}>\mathrm{G}^{\prime \prime}\right)$ at different frequecy values and $37^{\circ} \mathrm{C}$. Prepared gels resulted in preparations with desirable rheological features as well as texture (appropriate hardness, compressibility, adhesiveness, cohesiveness and elasticity) properties, which could benefit the therapeutic efficacy, by increasing the residence time and easiness for local application on the buccal mucosa. Additionally, the developed preparations exhibited sustained drug release up to $72 \mathrm{~h}$ as intended for these systems. Optimized formulation containing $14 \% \mathrm{w} / \mathrm{v}$ poloxamer 407 and $0.4 \% \mathrm{w} / \mathrm{v}$ gellan gum exhibited desired characteristics (mechanical and rheological properties) for developing buccal drug delivery systems. Thus, buccal dexamethasone loaded mucoadhesive in situ gel was found to be a promising formulation.

KEYWORDS: Dexamethasone; gellan gum; poloxamer; in situ gel; buccal drug delivery.

\section{INTRODUCTION}

Use of the oral mucosa for drug delivery has many positive factors: it is very accessible and responsive, as well as being diverse and dynamic. The positive features for drug delivery include that it is very vascular and therefore encourages a systemic effect. It also avoids first-pass metabolism and has fairly low enzymatic activity, which may result in increased bioavailability. Patient compliance may also be greater in orally delivered drugs [1-3]. Furthermore, local treatment to the oral mucosa is commonly used for treating fungal and bacterial infections, in addition to dental, periodontal and gum diseases and so forth [4]. However, one disadvantage of buccal drug delivery is that the drug remains at the site of action for only a brief period of time and therefore multiple dosage regimens are often needed to be effective [5].

Mucoadhesive in situ gels are drug carrier systems which are liquid prior to application and are converted into gel form after application. The most important advantages of mucoadhesive in situ gels is that they provide easiness of application, enhance the bioavailability, reduce the dose concentration and frequency and improve the patient compliance and comfort and sustained and prolonged action. Also, these systems are not too complex and the manufacturing processes is simple and cheap. The formulations provide covering substantially all oral cavity when they are sprayed into the mouth. Then the mucoadhesive polymers gelling at body temperature and adhering to oral mucosa and finally providing the active agent in an improved and effective way for treatment of the diseases [6,7].

In this work, mucoadhesive in situ gels were formulated using poloxamer (Plx) 407 and gellan gum (GG). Dexamethasone (DEX), a poor-water soluble glucocorticoid, was used as a model drug, since it is used clinically as an anti-inflammatory and immunosuppressive agent [8]. Relevant data have shown that dexamethasone has a certain effect in the treatment of oral ulcers [9]. Furthermore, DEX ointment has been used as a topical glucocorticoid agent to treat oral ulcers for many years [10]. For this reason, mucoadhesive in situ gels containing DEX were prepared for patient comfort.

How to cite this article: Rençber S, Karavana SY. Formulation and optimization of gellan gum-poloxamer based dexamethasone mucoadhesive in situ gel. J Res Pharm. 2020; 24(4): 529-538. 
Poloxamer (Plx) 407 is composed of $70 \%$ polyethyleneoxide and $30 \%$ polypropyleneoxide. It is frequently used, due to its low toxicity, high solubilizing capacity and excellent drug-release properties. This also means that it could be used in controlled drug delivery systems [11-13].

GG is a water-soluble, mucoadhesive, linear, anionic deacetylated exocellular bacterial polysaccharide produced by pseudomonas elodea $[7,14]$. It was primarily used as a stabilizer and thickening or gelling agent, and has been added to many different foods due to these properties. More recently, GG has been investigated as a polymer in pharmaceutical technology due to its biocompatibility, biodegradability and low cytotoxicity. It is able to form soft gels at low concentrations $[15,16]$.

The objective of this study was to assess the potential use of these polymers in controlled drug delivery of DEX in the oral mucosa, using a straightforward method and through assessing the properties of mucoadhesive in situ gels.

\section{RESULTS AND DISCUSSION}

In our previous study, DEX loaded poly(D,L-lactic-co-glycolic acid) (PLGA) nanoparticles (NPs) were successfully prepared using the emulsification/solvent evaporation method for the local treatment of oral precancerous lesions [17]. NPs with different rates of PLGA showed adequate properties in relation to $\mathrm{pH}$, particle size, polydispersite index, zeta potential, encapsulation efficiency, in vitro drug release, stability, ex vivo drug diffusion and cell culture cytotoxicity. In the present study, in situ gels were successfully prepared using Plx 407 and GG improve for the patient compliance and comfort. In situ gels offer several advantages such as easy to administer into the desired body cavities, high spreadability at certain temperatures, a reduction in the frequency of administration, improve patient compliance and comfortable in comparison to conventional dosage forms [6,7].

\subsection{Measurement of gelation temperature}

The gelling temperature of in situ gelling systems is one of the prime goal. For drug delivery it is ideal for the in situ gel to be sol state at room temperature, thereby facilitating administration of the drug, and then for the formulation to rapidly form a gel when in the oral cavity. Moreover, these gels should not dissolve, but rather remain in the gel form for a length of time [18].

The gelation temperatures of in situ gel formulations have been considered to be suitable if they are in the range of body temperature. Gelation temperature range suitable for mucosal formulations is $30-36^{\circ} \mathrm{C}$ [19]. In order to create these desired properties, the optimum concentration of the gel base and complexing agents will need to be known. Changes in micellar number due to temperature changes is known to cause gelation of Plx. Due to the negative solubility co-efficient of these micelles, an increase in temperature leads to an increase in the number of micelles formed. At high temperatures there are sufficient micelles in a small space so that the micelles can no longer move and it therefore forms a gel. Gelation occurs due to changes which take place in the centre of the micelle, where it undergoes changes in the methyl groups of the polymer side chains and water is expelled. At the different concentrations of Plx 407 gelation temperatures of the formulations were obtained. It was found that the gelation temperature of formulations decreased with an increase in the concentration of the thermosensitive polymer Plx 407 [20]. However, gelation temperature of G7 and G8 formulations was not influenced by Plx 407 concentration. The gellation temperatures of prepared mucoadhesive in situ gels were shown in Figure 1. The gelling temperature of the formulations ranged from $28.613 \pm 0.026$ to $39.191 \pm 0.025^{\circ} \mathrm{C}$. As seen in Table 2, G2, G3, G4, G6, G7 and G8 coded formulations had $30-37^{\circ} \mathrm{C}$ gelation temperature. However, it was decided that the most suitable formulations were G6, G7 and G8 coded in situ gel formulations by looking at their organoleptic (clarity) and rheological properties. The gelation temperature of G6, G7 and G8 coded formulations were found $35.151 \pm 0.038^{\circ} \mathrm{C}, 30.653 \pm 0.032^{\circ} \mathrm{C}$ and $31.184 \pm 0.016^{\circ} \mathrm{C}$, respectively. Formulation G6 containing Plx $407(10 \%)$ showed excellent gelation as compared to the G7 containing Plx 407 (12\%) and G8 containing Plx 407 (14\%) due to increasing the concentration of Plx 407 for the same GG concentration. The GG and Plx 407 concentration in the formulations was determined as $0.4 \%$ and $10-12-14 \%$ based on the gelation temperature studies, respectively. Therefore, studies continued with these formulations. Baloglu et al. [19] prepared in situ gel formulations using Plx 407 and Plx 188 for use as drug delivery platform via mucosal route. In this study, Plx 407 and Plx 188 were used alone and together. The results showed that with the increase in the concentration of Plx 407, the gelation capacity was decreased. In another study, Garala et al. [20] was developed in situ gels containing Chlorhexidine hydrochloride using Plx 188, Plx 407, GG, and Carbopol 934P for the treatment of periodontal disease. Gelation temperatures for Plx 188 and Plx 407 gels were 
observed for the different concentration range of polymer, and it was found that the gelation temperature of formulation decreased with increasing concentration of polymer.

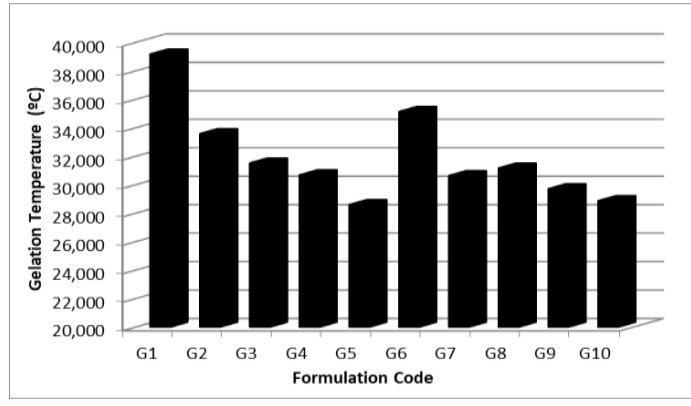

Figure 1. The gelation temperature of the formulations.

\subsection{Drug content}

The method for analysis was designed and DEX underwent validation studies. The acceptance criteria of $2 \%$ standard deviation was used, and the analysis method for the determination of the assay was verified if the standard deviation was lower than the acceptance criteria. The limit of detection (LOD) of DEX was $0.182 \mu \mathrm{g} / \mathrm{mL}$ and the limit of quantification (LOQ) of DEX was $0.487 \mu \mathrm{g} / \mathrm{mL}$. The used method for DEX analysis was found to be linear $\left(\mathrm{r}^{2}=1\right)$.

The drug content of all mucoadhesive in situ gels containing DEX was found to be within the acceptable range of 95.307-97.026\%, which indicates content uniformity (Table 2).

\subsection{Determination of $\mathrm{pH}$}

$\mathrm{pH}$ is a very important factor for buccal formulations. The normal physiological $\mathrm{pH}$ of the buccal mucosa ranges from 5.5-7.5 [17,18]. The $\mathrm{pH}$ of all in situ gel formulations containing DEX was observed in the range of 6.72-6.82 (Table 1). There was no need for $\mathrm{pH}$ adjustment by any alkalinizing agent. Besides, an acidic or alkaline formulation may irritate buccal mucosa, and hence, this parameter assumes importance in the formulation of mucoadhesive dosage forms [4,21]. The obtained $\mathrm{pH}$ values of formulations are considered acceptable to avoid the risk of irritation upon application to the buccal mucosa.

Table 1. Drug content and $\mathrm{pH}$ of gel formulations.

\begin{tabular}{ccc}
\hline Formulation Code & Drug content (\%) \pm S.D. & pH \pm S.D. \\
\hline G6 & $97.026 \pm 1.378$ & $6.82 \pm 0.01$ \\
G7 & $95.426 \pm 2.938$ & $6.74 \pm 0.02$ \\
G8 & $95.307 \pm 1.391$ & $6.72 \pm 0.02$ \\
\hline
\end{tabular}

\subsection{Rheological studies}

The rheological properties for the gel formulations would be important for predicting their behavior/spreadability in vivo conditions. Rheological properties have fundamental in retention on the buccal surface for gels efficacy. The better elastic characteristic and enhancement the rheologic properties of the mucoadhesive gel extend the residence time at desired area [22,23]. The sufficient retention and distribution capacity in the buccal mocosa is provided the selection of correct viscosity of the formulation. For buccal delivery of a drug the viscosity of the in situ gel will need to be low at the time of application to the oral mucosa, but a high viscosity is required thereafter in order for the drug to remain in the area. Representative viscosity curves of prepared mucoadhesive in situ gel formulations were graphically presented in Figure 2. As anticipated due to its thermoresponsiveness, at $37 \pm 0.1^{\circ} \mathrm{C}$ all of the preparations showed non-Newtonian pseudoplastic flow, as is expected for Plx above the sol-gel transition temperature. It is precisely the non-Newtonian pseudoplasticity flow that is beneficial in buccal application, as it causes the gel to break down and disperse over the oral mucosa and then after being applied it regains its initial structure [18,23-25]. In addition, at $25 \pm 0.1^{\circ} \mathrm{C}$ the formulations demonstrated Newtonian flow. With an increase in shear strain the viscosity decreases, as seen in shear thinning. Our findings demonstrated sheer thinning at $37 \pm 0.1^{\circ} \mathrm{C}$, in line with the literatures [26-29]. In our study the G8 formulations gave rise to the highest viscosity value and had the most consistent gel structure. 


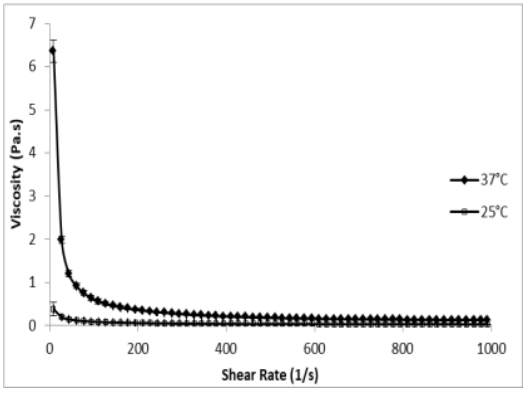

G6

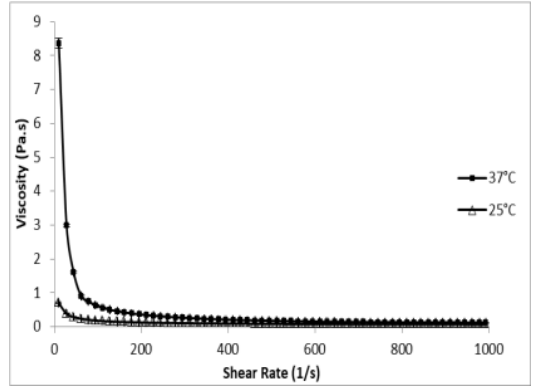

G7

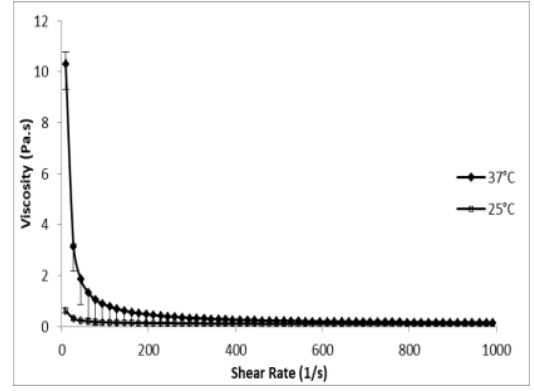

G8

Figure 2. Viscosity curves of the formulations at $25^{\circ} \mathrm{C}$ and $37^{\circ} \mathrm{C}$

The oscillatory properties of semisolid systems are influencing the application and retention on the buccal mucosa. The good elastic character and the beneficial rheologic properties prolong the residence time of the drug delivery system in the buccal mucosa. The storage modulus, $\mathrm{G}^{\prime}$, represents the elastic component of a viscoelastic material and the loss modulus, $G^{\prime \prime}$, refers to the viscous portion. These values are obtained when an oscillatory force is applied to the formulations and the strain is measured. When a single oscillatory force is applied semi-solid formulations do not have time to separate out and therefore $G^{\prime}$ will be higher than $G^{\prime \prime}[22,30]$. All optimum formulations were frequency independent solid-like spectra $\left(G^{\prime}>G^{\prime \prime}\right)$ at $37^{\circ} \mathrm{C}$ (Figure 3 ).

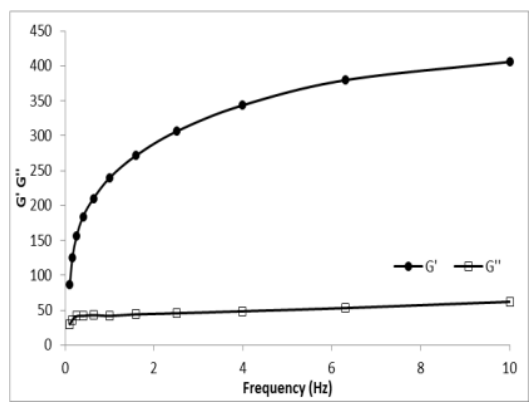

G6

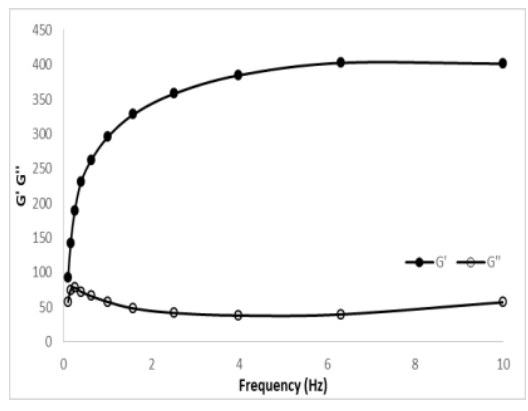

G7

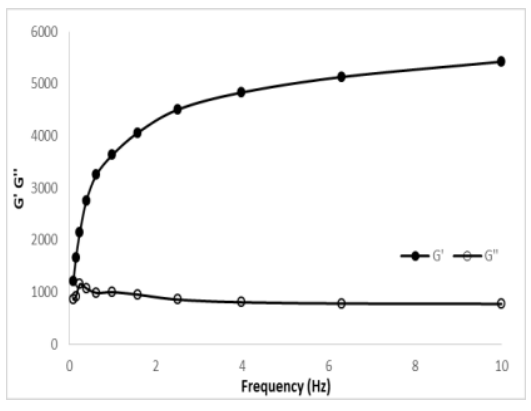

G8

Figure 3. Frequency-dependent changes of viscoelastic properties of the formulations at $37^{\circ} \mathrm{C}$

The value of phase angle $\left(\tan \delta=G^{\prime \prime} / G^{\prime}\right)$ is representing the relative contribution of viscous components to the mechanical properties of the formulations with values lower than 1 , representing a solid gel response (Figure 4) [30].

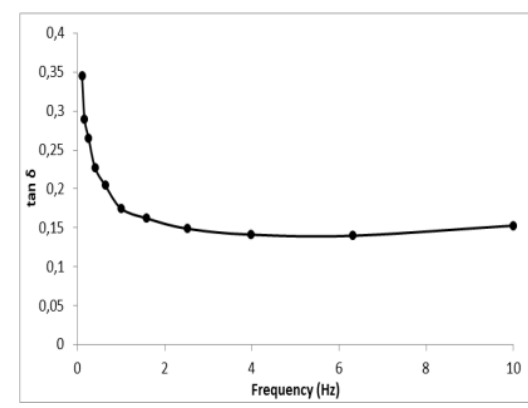

G6

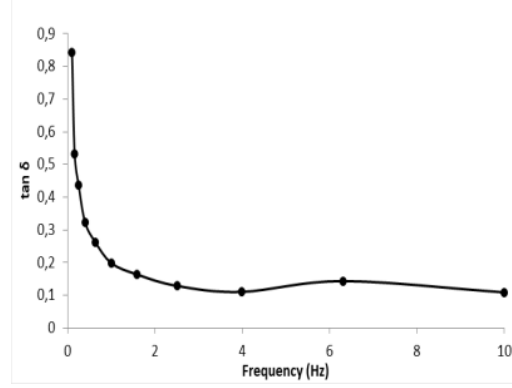

G7

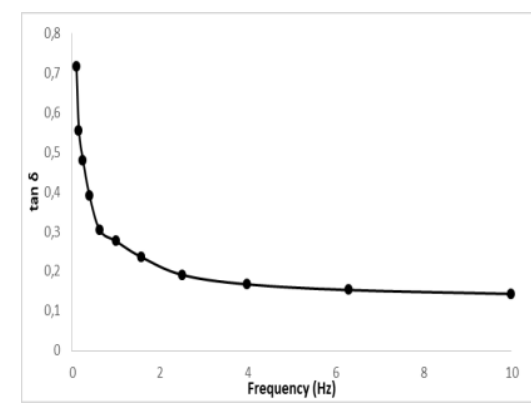

G8

Figure 4. Frequency-dependent changes of $\tan \delta$ values of the formulations at $37^{\circ} \mathrm{C}$.

\subsection{Mechanical properties of formulations}

To better understand the physical and mechanical properties of gel formulations a Texture Profile Analysis (TPA) can be carried out. The TPA can be used to predict the behavior of the gels in different 
conditions and can also be used to understand and identify the physical and chemical interactions between the different gel components. A successful buccal gel formulation must have the right mechanical properties to provide the patient with the most effective and efficient treatment. TPA provides information on the following parameters: compressibility, hardness, adhesiveness, elasticity and cohesiveness [31-34]. Table 2 represented the obtained results of mechanical properties from textural analysis.

The maximum force needed to achieve a specific degree of deformation of a gel is known as the hardness, thus it provides information about the buccal application of the gel. As the hardness value increases, the in situ gel formation will be thicker and have higher consistency. The effort needed to deform the gel in the first pass of the probe is termed compressibility. In terms of ease of use, a gel will need to have low hardness and compressibility values to facilitate application and allow its spread on the site of action. The disadvantage of very low hardness and compressibility is that low values mean the gel does not remain in the oral cavity for the desired time (retention) [31,35,36].

Adhesion is the attraction between the surface formulation and the probe and therefore the effort needed to overcome this reaction is the adhesiveness. In order to satisfy the need for retention of the formulations at the site of action, the gel must have high adhesiveness.

The ratio of the positive force area during the second compression cycle to that of the first compression cycle is known as cohesiveness. This parameter assesses the ability of the gel to recuperate after it is applied [37]. The higher the cohesiveness value, the more complete the reconstruction of the gel after application. A high value will translate in increased efficacy of the application at the site of action [38, 39].

The ratio of time needed to obtain maximum structural deformation on the second compression cycle to the first compression cycle is the elasticity. A high value of elasticity in TPA refers to a low elasticity of the formulation. Retention of the gel at the desired site is increased with higher values of elasticity as this means the formulation tends to reconstruct at the site $(34,35,38]$.

The G8 coded formulation demonstrated higher values of hardness, adhesiveness, and cohesiveness than G6 and G7 coded formulations, probably because its polymeric concentration is also greater. However, the compressibility and elasticity values of G8 coded formulation decreased than G6 and G7 coded formulations due to the increase in the polymer concentration. The results from our study were in accordance with the literatures [31,38]. Swain et al. [31] developed Moxifloxacin Hydrochloride loaded in situ gels with Plx, GG and carbopol for the treatment of periodontitis. The hardness values of these formulations were increased as the concentration of polymer increases.

Table 2. Mechanical properties of gel formulations.

\begin{tabular}{cccccc}
\hline Code & $\begin{array}{c}\text { Hardness } \\
(\mathbf{m N}) \pm \text { S.D. }\end{array}$ & $\begin{array}{c}\text { Compressibility } \\
\text { (mN.s) } \pm \text { S.D. }\end{array}$ & $\begin{array}{c}\text { Adhesiveness } \\
\text { (mN.s) } \pm \text { S.D. }\end{array}$ & $\begin{array}{c}\text { Cohesiveness } \\
\pm \text { S.D. }\end{array}$ & $\begin{array}{c}\text { Elasticity } \\
\pm \text { S.D. }\end{array}$ \\
\hline G6 & $45.653 \pm 0.635$ & $183.521 \pm 1.533$ & $273.521 \pm 0.851$ & $0.898 \pm 0.043$ & $0.985 \pm 0.025$ \\
G7 & $53.232 \pm 0.187$ & $182.308 \pm 0.549$ & $305.895 \pm 0.292$ & $1.021 \pm 0.061$ & $1.003 \pm 0.011$ \\
G8 & $60.760 \pm 3.736$ & $180.452 \pm 1.415$ & $341.699 \pm 2.613$ & $1.210 \pm 0.288$ & $1.039 \pm 0.110$ \\
\hline
\end{tabular}

\subsection{In vitro drug release studies}

The in vitro release of drug from the dosage form plays an important role in the drug delivery systems and in determining the therapeutic effect of the drug. In order to plan and prepare for the use of the gel formulation in vivo, an in vitro study needs to be carried out [40].

The in vitro release profiles of DEX were evaluated in $\mathrm{pH} 6.8$ phosphate buffer at $37^{\circ} \mathrm{C}$ and the results were displayed in Figure 5. As can be seen, the release of DEX was in range of $42-46 \%$ over 8 hours. In 24 hours, the release rates of DEX from G6, G7 and G8 reached 76.026, 73.128 and 72.618\%, respectively. In addition, at the end of 72 hours, the release rates from G6, G7 and G8 were 100, 100 and 93.222\%, respectively. These results indicated that combination of mucoadhesive agents with Plx 407 could prolong drug action time in buccal mucosa due to the increase of viscosity with addition of GG. In our previous DEX loaded NP study, after $8 \mathrm{~h}$, the drug release in formulations was found to be approximately 60\% [17]. Mucoadhesive in situ gel formulations showed a slower drug release profile than nanoparticles.

The literatures have suggested that gel viscosity affects drug release, showing that gels with greater viscosity demonstrate slower drug release [38,41-43]. Cavallari et al. [44] showed that a gel barrier forming on the surface of the formulation causes a high ratio of hydroxypropyl methyl cellulose and slower drug release. Topical application of Moxifloxacin Hydrochloride in a thermosensitive in situ gel was designed by 
Swain et al. [31] and the findings showed that the concentration of GG and Plx had an effect on the in vitro release of the drug.



Figure 5. In vitro drug release of formulations.

\section{CONCLUSION}

In present research work mucoadhesive in situ buccal gel formulations containing DEX was developed with combination of gellan gum and Plx 407. It was seen that as the concentration of Plx 407 was increased, the gelation temperature of formulations decreased. GG tends to decrease the gelation temperature of Plx 407. A modulation of the gelation temperature to reach the desired range $\left(30^{\circ} \mathrm{C}-37^{\circ} \mathrm{C}\right)$ was achieved through the use of a combination of the Plx 407 and GG. Moreover, mucoadhesive in situ gels resulted in formulations with desirable rheological and texture properties that can benefit the therapeutic efficacy of a drug administered by buccal route, increasing the retention time and the easiness for local application in the buccal mucosa. Considering the viscosity and mechanical properties of gels, these results suggest that G8 coded gel formulation may promote greater residence time on the mucosa, being more advantageous for buccal administration. Furthermore, the release profile studies showed that the DEX could be released from the formulation over a prolonged period of time $(72 \mathrm{~h})$. Thus from the above results it can be concluded that a mucoadhesive in situ gel of DEX can be formulated using optimum quantity of Plx 407 and GG combination (14 and $0.4 \%$, respectively) of both to have a increase in buccal residence time and patient comfort.

\section{MATERIALS AND METHODS}

DEX was generously donated by Pharmacia\&Upjohn Company LLC (A Subsidiary of Pfizer Inc, USA). GG was obtained from Sigma-Aldrich (St. Louis, MO). Plx 407 was donated by BASF Chemical Company (Germany). All the other chemicals were of analytical grade.

\subsection{Preparation of mucoadhesive in situ gel formulations}

In situ gels were prepared by dispersing the polymer in distilled water. GG powder was dispersed in distilled water maintained at $50^{\circ} \mathrm{C}$ with vigorous stirring using magnetic stirrer. The dispersion was stirred at $50^{\circ} \mathrm{C}$ for 20 minutes to facilitate the complete hydration of GG. The solution was cooled down to $25^{\circ} \mathrm{C}$. The required amount of DEX was added to GG solution with continuous stirring until the entire drug was dispersed. Then required amount of Plx 407 was added with continuous mild stirring for 5 minutes. The formulation containing partially dissolved Plx 407 were stored in the refrigerator until entire polymer gets completely dissolved. The prepared formulation store at cool place [26,31,45]. The composition of the formulations was presented in Table 3.

\subsection{Measurement of gelation temperature}

Gelation temperature and gelation time were determined with rheometer (TA Discovery HR-1 hybrid rheometer, Newcastle, Britain). The geometry was a stainless steel plate/plate (diameter $40 \mathrm{~mm}$ ) and it provided a homogeneous shear of the gel. The sol-gel transition temperatures of the gels were determined from oscillation measurements with a fixed frequency of $0.01 \mathrm{~Hz}$. The samples were heated with a rate of $2^{\circ} \mathrm{C} / \mathrm{min}$, within a range of $20-50^{\circ} \mathrm{C}$ during the measurement $[22,46]$. 
Table 3. The composition of in situ gel formulations.

\begin{tabular}{cccc}
\hline Formulation Code & DEX (\%) & GG (\%) & Plx $407(\%)$ \\
\hline G1 & 0.1 & 0.2 & 10 \\
G2 & 0.1 & 0.2 & 12 \\
G3 & 0.1 & 0.2 & 14 \\
G4 & 0.1 & 0.2 & 15 \\
G5 & 0.1 & 0.2 & 16 \\
G6 & 0.1 & 0.4 & 10 \\
G7 & 0.1 & 0.4 & 12 \\
G8 & 0.1 & 0.4 & 14 \\
G9 & 0.1 & 0.4 & 15 \\
G10 & 0.1 & 0.4 & 16 \\
\hline
\end{tabular}

\subsection{Determination of $\mathrm{pH}$}

The calibrated $\mathrm{pH}$ meter (Hana Instruments HI 221) was used to determine the $\mathrm{pH}$ values of formulation at room temperature to examine the compatibility of gels for buccal mucosa.

\subsection{Drug content}

To determine the drug content, $0.25 \mathrm{~g}$ of mucoadhesive in situ gel sample was taken from top, middle, and bottom of the gel and extracted by addition of $10 \mathrm{~mL}$ of phosphate buffer $(\mathrm{pH} 6.8)$ followed by mixing for 48 hours. The drug content was analyzed per validated HPLC method $(n=5)$.

A validated HPLC method was used for determining the DEX amount (Hewlett-Packard Agilent 1100, Agilent Technologies, Santa Clara, CA, USA-equipped with UV-Visible detector). A $250 \mathrm{~mm} \times 4.6 \mathrm{~mm}(5 \mu \mathrm{m}$ particle size) reversed-phase $\mathrm{C} 18$ column was used for separation and quantitation. As mobile phase methanol: water: triethylamine (70:30:0.6, v/v/v) was used and $\mathrm{pH}$ of the mixture was adjusted to $3.0 \pm 0.05$ with orthophosphoric acid. The flow rate was set as $0.9 \mathrm{~mL} / \mathrm{min}$ at $25^{\circ} \mathrm{C}$. UV detection was made at $240 \mathrm{~nm}$ $[47,48]$. The validation was performed following the ICH guidelines including determination of linearity, specificity, accuracy, precision (repeatability and reproducibility), stability, limit of detection, and limit of quantification [49].

\subsection{Rheological studies}

Rheological studies were performed using a rheometer device (TA Discovery HR-1 Hybrid Rheometer). The analysis was performed, in flow mode using parallel plate geometry (gap: $1 \mathrm{~mm}$ ) at room temperature. Upward and downward flow curves were measured ranging from $10 \mathrm{~s}^{-1}$ to $1000 \mathrm{~s}^{-1}[22,23,50]$.

The stress sweep studies were used to determine the yield stress of gel formulations to predict the stress required to initiate flow. The stress was gradually conducted over the range of 0.1-1000 $\mathrm{Pa}$ and at a frequency of $1 \mathrm{~Hz}$. The resulting viscoelastic parameters were monitored and determined its linear viscoelastic region, where the stress was directly proportional to the strain and the storage modulus remained constant. The yield stress value was detected.

The oscillatory analysis was performed after determination of its linear viscoelastic region. Frequency sweep analysis was performed over the frequency range of $0.1-10.0 \mathrm{~Hz}$ following application of constant stress. Elastic (storage) modulus ( $\left.G^{\prime}\right)$, viscous (loss) modulus (G") and the loss tangent ( $\tan \delta$ ) were examined $[22,51,52]$.

\subsection{Mechanical properties of formulations}

The mechanical properties (hardness, compressibility, adhesiveness, cohesiveness and elasticity) were performed using a software-controlled penetrometer, TA-XT Plus texture analyzer (Stable Micro Systems, $\mathrm{UK}$ ), with a $500 \mathrm{~g}$ load cell at $37 \pm 0.5^{\circ} \mathrm{C}$. Each formulation was transferred into universal bottle and kept in the ultrasonic water bath to remove air bubbles for $20 \mathrm{~min}$. The Perspex probe was twice compressed into each formulation at a defined rate of $2 \mathrm{~mm} \cdot \mathrm{s}^{-1}$ to a depth of $15 \mathrm{~mm}$. A delay period of $15 \mathrm{sec}$ was allowed between the two compressions. Mechanical properties of the gel formulations were derived from the resultant force-time curve [34]. $(\mathrm{n}=5)$. 


\subsection{In vitro drug release studies}

Dialysis bag method was used for the in vitro drug release study of in situ gels. In situ gel containing DEX was put into the Spectra/Por Regenerated Cellulose Dialysis Membrane Tubes (12.000-14.000 MWCO). The release medium was $100 \mathrm{~mL}$ of phosphate buffer $(\mathrm{pH}$ 6.8) under sink conditions. In order to simulate the oral mucosa temperature, the temperature was set at $37^{\circ} \mathrm{C} \pm 0.5^{\circ} \mathrm{C}$ and the stirring speed was kept at $300 \mathrm{rpm}$. At defined time intervals, samples were withdrawn, and the DEX content of each sample was analyzed using a validated HPLC method $(n=5)$.

Acknowledgements: This study was supported by a research grant from Ege University (16/ECZ/015). We would like to acknowledge E.U. Pharmaceutical Sciences Research Center for enabling us to use its laboratory instruments.

Author contributions: Concept - S.R., S.Y.K.; Design - S.R., S.Y.K.; Supervision - S.R., S.Y.K.; Resources - S.R.; Materials - S.R.; Data Collection and/or Processing - S.R.; Analysis and/or Interpretation - S.R.; Literature Search S.R.; Writing - S.R., S.Y.K.; Critical Reviews - S.R., S.Y.K.

Conflict of interest statement: The authors declared no conflict of interest in the manuscript.

\section{REFERENCES}

[1] Yakubov GE, Gibbins H, Proctor GB, Carpenter GH. Oral mucosa: physiological and physicochemical aspects. In: Khutoryanskiy VV. (Eds). Mucoadhesive Materials and Drug Delivery Systems. John Wiley \& Sons. 35, Chichester, West Sussex, UK, 2014, chapter 1. [CrossRef]

[2] Sankar V, Hearnden V, Hull K, Juras DV, Greenberg M, Kerr A, Lockhart PB, Patton LL, Porter S, Thornhill M. Local drug delivery for oral mucosal diseases: Challenges and opportunities. Oral Dis. 2011; 17(1): 73-84. [CrossRef]

[3] Silva AC, Santos D, Ferreira D, Lopes CM. Lipid-based nanocarriers as an alternative for oral delivery of poorly water-soluble drugs: Peroral and mucosal routes. Curr Med Chem. 2012; 19: 4495-4510. [CrossRef]

[4] Shojaei AH. Buccal mucosa as a route for systemic drug delivery: A review. J Pharm Pharm Sci. 1998; 1: 15-30.

[5] Hearnden V, Sankar V, Hull K, Juras DV, Greenberg M, Kerr AR, Lockhart PB, Patton LL, Porter S, Thornhill MH. New developments and opportunities in oral mucosal drug delivery for local and systemic disease. Adv Drug Deliv Rev. 2012; 64(1): 16-28. [CrossRef]

[6] Almeida H, Amaral MH, Lobao P, Sousa Lobo JM. In situ gelling systems: a strategy to improve the bioavailability of ophthalmic pharmaceutical formulations. Drug Discov Today. 2014; 19(4): 400-412. [CrossRef]

[7] Dhir S, Saffi KA, Kamalpuria N, Mishra D. An overview of in situ gelling system. Int J Pharm Life Sci. 2016; 7(8): $5135-5156$

[8] Saviola G, Bonazzi S, Comini L, Abdi-Ali L. Dexamethasone is an "essential medicine". It is time to consider this drug in the treatment of rheumatic diseases. A narrative review. Acta Medica Mediterr. 2020; 36: 107-114. [CrossRef]

[9] Ruan JY, Li D, Tao H, Chunni D. Effects of dexamethasone on the EGF mRNA levels and inflammatory factors in rabbits with oral ulcers. Pharm Bioprocess. 2018; 6(3): 119-125.

[10] Zhang C, Liu Y, Li W, Gao P, Xiang D, Ren X, Liu D. Mucoadhesive buccal film containing ornidazole and dexamethasone for oral ulcers: In vitro and in vivo studies. Pharm Dev Tech. 2019; 24(1): 118-126. [CrossRef]

[11] Miyazaki S, Tobiyama T, Takada M, Attwood D. Percutaneous absorption of indomethacin from pluronic F-127 gels in rats. J Pharm Pharmacol. 1995; 47: 455-457. [CrossRef]

[12] Üstündağ Okur N, Yoltaş A, Yozgatlı V. Development and characterization of voriconazole loaded in situ gel formulations for ophthalmic application. Turk J Pharm Sci. 2016; 13(3): 311-317.

[13] Desai SD, Blanchard J. Evaluation of pluronic F127-based sustained-release ocular delivery systems for pilocarpine using the albino rabbit eye model. J Pharm Sci. 1998; 87: 1190-1195. [CrossRef]

[14] Osmałek T, Froelich A, Tasarek S. Application of gellan gum in pharmacy and medicine. Int J Pharm. 2014; 466(1-2): 328-340. [CrossRef]

[15] Oliveira JT, Martins L, Picciochi R, Malafaya PB, Sousa RA, Neves NM, Mano JF, Reis RL. Gellan gum: A new biomaterial for cartilage tissue engineering applications. J Biomed Mater Res A. 2010; 93: 852-863. [CrossRef] 
[16] Silva-Correia J, Oliveira JM, Caridade SG, Oliveira JT, Sousa RA, Mano JF, Reis RL. Gellan gum-based hydrogels for intervertebral disc tissueengineering applications. J Tissue Eng Regen Med. 2011; 5(6): e97-e107. [CrossRef]

[17] Rençber S, Aydın Köse F, Karavana SY. Dexamethasone loaded PLGA nanoparticles for potential local treatment of oral precancerous lesions. Pharm Dev Tech. 2020; 25(2): 149-158. [CrossRef]

[18] Elmowafy E, Cespi M, Bonacucina G, Soliman ME. In situ composite ion-triggered gellan gum gel incorporating amino methacrylate copolymer microparticles: A therapeutic modality for buccal applicability. Pharm Dev Tech. 2019; 24(10): 1258-1271. [CrossRef]

[19] Baloglu E, Karavana SY, Ay Senyigit Z, Guneri T. Rheological and mechanical properties of poloxamer mixtures as a mucoadhesive gel base. Pharm Dev Tech. 2011; 16(6): 627-636. [CrossRef]

[20] Garala K, Joshi P, Shah M, Ramkishan A, Patel J. Formulation and evaluation of periodontal in situ gel. Int J Pharm Investig. 2013; 3(1): 29-41. [CrossRef]

[21] Gousia Begum S, Sekar M. Formulation and evaluation of tinidazole mucoadhesive buccal gels. Int J Pharm Bio Sci. 2017; 8(2): 48-55. [CrossRef]

[22] Rençber S, Karavana SY, Ay Şenyigit Z, Eraç B, Hoşgör Limoncu M, Baloğlu E. Mucoadhesive in situ gel formulation for vaginal delivery of clotrimazole: Formulation, preparation and in vitro/in vivo evaluation. Pharm Dev Tech. 2017; 22(4): 551-561. [CrossRef]

[23] Chang JY, Oh YK, Choi H, Kim YB, Kim CK. Rheological evaluation of thermosensitive and mucoadhesive vaginal gels in physiological conditions. Int J Pharm. 2002; 241: 155-163. [CrossRef]

[24] Estanqueiro M, Amaral MH, Sousa Lobo JM. Comparison between sensory and instrumental characterization of topical formulations: Impact of thickening agents. Int J Cosmet Sci. 2016; 38: 389-398. [CrossRef]

[25] Silva AC, Amaral MH, Gonzalez-Mira E, Santos D, Ferreira D. Solid lipid nanoparticles (SLN)-based hydrogels as potential carriers for oral transmucosal delivery of risperidone: preparation and characterization studies. Colloids Surf B Biointerfaces. 2012; 93: 241-248. [CrossRef]

[26] Sapra P, Patel D, Soniwala M, Chavda J. Development and optimization of in situ periodontal gel containing Levofloxacin for the treatment of periodontal diseases. J Sci Innov Res. 2013; 2(3): 607-626.

[27] Jones DS, Woolfson AD, Brown AF, Coulter WA, McClelland C, Irwin CR. Design, characterisation and preliminary clinical evaluation of a novel mucoadhesive topical formulation containing tetracycline for the treatment of periodontal disease. J Control Release. 2000; 67: 357-368. [CrossRef]

[28] Stein GE, Mummaw N. Placebo-controlled trial of itraconazole for treatment of acute vaginal candidiasis. Antimicrob Agents Chemother. 1993; 37: 89-92. [CrossRef]

[29] Ustundag Okur N., Yozgatlı V., Senyigit Z. Formulation and detailed characterization of voriconazole loaded in situ gels for ocular application. J Fac Pharm Ankara. 2020; 44(1): 33-49. [CrossRef]

[30] Karavana SY, Gökçe EH, Rençber S, Özbal S, Pekçetin Ç, Güneri P, Ertan G.A new approach to the treatment of recurrent aphthous stomatitis with bioadhesive gels containing cyclosporine a solid lipid nanoparticles: In Vivo/in vitro examinations. Int J Nanomedicine. 2012; 7: 5693-5704. [CrossRef]

[31] Swain GP, Patel S, Gandhi J, Shah P. Development of moxifloxacin hydrochloride loaded in-situ gel for the treatment of periodontitis: in-vitro drug release study and antibacterial activity. J Oral Biol Craniofac Res. 2019; 9: 190-200. [CrossRef]

[32] De Souza Ferreira SB, Moço TD, Borghi-Pangoni FB, Junqueira MV, Bruschi ML. Rheological, mucoadhesive and textural properties of thermoresponsive polymer blends for biomedical applications. J Mech Behav Biomed Mater. 2015; 55: 164-178. [CrossRef]

[33] Carvalho FC, Bruschi ML, Evangelista RC, Gremião MPD. Mucoadhesive drug delivery systems. Braz J Pharm Sci. 2010; 46: 1-18. [CrossRef]

[34] Jones DS, Woolfson AD, Brown AF. Textural, viscoelastic and mucoadhesive properties of pharmaceutical gels composed of cellulose polymers. Int J Pharm. 1997; 151: 223-233. [CrossRef]

[35] Bruschi ML, Jones DS, Panzeri H, Gremião MPD, Freitas O, Lara EHG. Semisolid systems containing propolis for the treatment of periodontal disease: In vitro realease kinetics, syringeability, rheological, textural and mucoadhesive properties. J Pharm Sci. 2007; 99: 4215-4227. [CrossRef]

[36] De Souza Ferreira SB, Bassi da Silva J, Borghi-Pangoni FB, Junqueira MV, Bruschi ML. Linear correlation between rheological, mucoadhesive and textural properties of thermoresponsive polymer blends for biomedical applications. J Mech Behav Biomed Mater. 2017; 68: 265-275. [CrossRef] 
[37] Jones DS, Woolfson AD, Djokic J, Coulter WA. Development and mechanical characterization of bioadhesive semisolid, polymeric systems containing tetracycline for the treatment of periodontal diseases. Pharm Res. 1996; 13: 1734-1738. [CrossRef]

[38] Cevher E, Taha MAM, Orlu M, Araman A. Evaluation of mechanical and mucoadhesive properties of clomiphene citrate gel formulations containing carbomers and their thiolated derivatives. Drug Deliv. 2008, 15(1): 57-67. [CrossRef]

[39] Tan YTF, Peh KK, Al-Hanbali O. Effect of carbopol and polyvinylpyrrolidone on the mechanical, rheological and release properties of bioadhesive polyethylene glycol gels. AAPS PharmSciTech. 2000; 1: 1-10. [CrossRef]

[40] Esposito E, Menegatti E, Cortesi R. Hyaluronan-based microspheres as tools for drug delivery: A comparative study. Int J Pharm. 2005; 288: 35-49. [CrossRef]

[41] Karavana SY, Ay Senyigit Z, Hilmioglu-Polat S, Metin DY, Zekioglu O, Baloglu E. Mucoadhesive in situ gel formulations of miconazole nitrate for the treatment of mucosal candidiasis. Lat Am J Pharm. 2012; 31: 821-829.

[42] Ay Senyigit Z, Karavana SY, Eraç B, Gursel O, Hosgor Limoncu M, Baloglu E. Evaluation of chitosan based vaginal bioadhesive gel formulations for antifungal drugs. Acta Pharm. 2014; 64: 139-156. [CrossRef]

[43] Tas C, Özkan Y, Savaser A, Baykara T. In vitro release studies of chlorpheniramine maleate from gels prepared by different cellulose derivatives. Il Farmaco. 2003; 58: 605-611. [CrossRef]

[44] Cavallari C, Fini A, Ospitali F. Mucoadhesive multiparticulate patch for the intrabuccal controlled delivery of lidocaine. Eur J Pharm Biopharm. 2013; 83(3): 405-14. [CrossRef]

[45] Cao SL, Zhang QZ, Jiang XG. Preparation of ion-activated in situ gel systems of scopolamine hydrobromide and evaluation of its antimotion sickness efficacy. Acta Pharmacol Sin. 2007; 28(4): 584-90. [CrossRef]

[46] Karavana SY, Rençber S, Ay Şenyiğit Z, Baloğlu E. A new in-situ gel formulation of itraconazole for vaginal administration. Pharmacol Pharm. 2012; 3: 417-426. [CrossRef]

[47] Goyal RN, Gupta VK, Chatterjee S. Fullerene-C60-modified edge plane pyrolytic graphite electrode for the determination of dexamethasone in pharmaceutical formulations and human biological fluids. Biosens Bioelectron. 2009; 24(6): 1649-1654. [CrossRef]

[48] Desai UH, Patwari AH, Maradiya JK, Sathawara MK, Suhagia BN, Rathod IS. RP-HPLC method for simultaneous estimation of ciprofloxacin and dexamethasone in eye/ear drops. Int J Pharm Sci Res. 2013; 5(2): 62-66.

[49] International Conference Harmonisation $\quad$ (ICH) http://www.ich.org/LOB/media/MEDIA417.pdf.

[Online]

[50] Sandri G, Rossi S, Ferrari F, Bonferonia MC, Muzzarelli C, Caramella C. Assessment of chitosan derivatives as buccal and vaginal penetration enhancers. Eur J Pharm Sci. 2004; 21: 351-359. [CrossRef]

[51] Andrews GP, Gorman SP, Jones DS. Rheological characterisation of primary and binary interactive bioadhesive gels composed of cellulose derivatives designed as ophthalmic viscosurgical devices. Biomater. 2005; 26(5): 571-580. [CrossRef]

[52] Andrews GP, Jones DS. Rheological characterization of bioadhesive binary polymeric systems designed as platforms for drug delivery implants. Biomacromolecules. 2006; 7: 899-906. [CrossRef]

This is an open access article which is publicly available on our journal's website under Institutional Repository at http://dspace.marmara.edu.tr. 